\title{
GEO-ELECTRICAL MAPPING OF BEACHROCK IN VATERA BEACH, LESVOS
}

\author{
Meligonitis R. ${ }^{1,2}$, Galanopoulos D. ${ }^{2}$, Hasiotis T. ${ }^{1}$ and Velegrakis A. ${ }^{1}$ \\ ${ }^{1}$ Department of Marine Sciences, University of the Aegean, University Hill, 81100, Mytilene, \\ Lesvos,meligonitis@marine.aegean.gr,hasiotis@marine.aegean.gr,afv@aegean.gr \\ ${ }^{2}$ Ministry of Marine \& Island Policy, General Secretariat of Aegean \& Island Policy, 2 Mikras \\ Asias,81100,Mytilene,Greece,ramel@ypai.gr,dgal@ypai.gr
}

\begin{abstract}
Beachrock $(B r)$ is encountered on the coastal zones, playing an important but also complex role in their morphodynamic evolution. Although Br has been widely studied, two important issues require further investigation. The first concerns the importance of the interaction of the dynamically changing coastal environment with the temporal changing surficial and underground hydrogeological balance. The second has to do with the spatial distribution and the evolution of Br with respect to the specific "host" coastal zone geo-environment. This paper designates the electrical resistivity method as a tool that contribute in arguing in the abovementioned issues. The research comprised subsurface measurements with the DC resistivity method along two profiles located on Vatera beach (Lesvos Island), where there is a significant $\mathrm{Br}$ outcrops. Twelve geoelectric soundings were carried out using the Axial Pole-Dipole electrode array. The electrical resistively measurements permitted an indirect estimation of TDS, which depicts the coastal interface of fresh water-sea water. The interpreted geoelectric model shows two thin formations attributed to $\mathrm{Br}$. The first is the inland extension of the Br outcrop and the second it is believed to be a primary stage of Br build up.
\end{abstract}

Keywords: beachrock, coastal zone, geophysics, prospecting, Lesvos.

\section{Пєрі́ $\eta \psi \eta$}

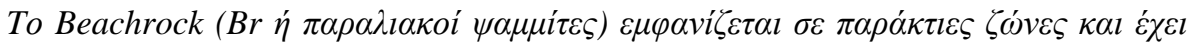

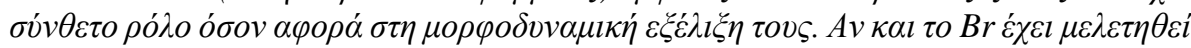

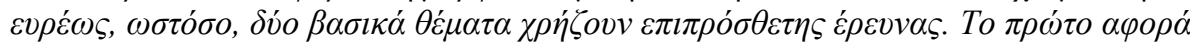

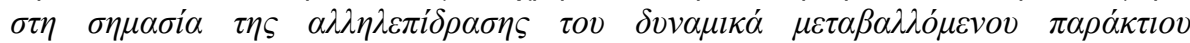

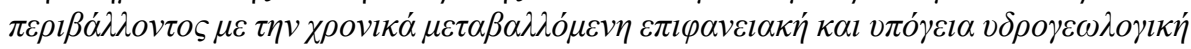

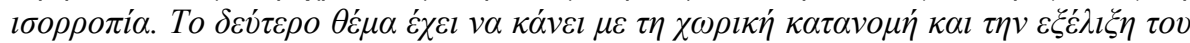

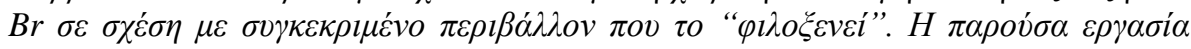

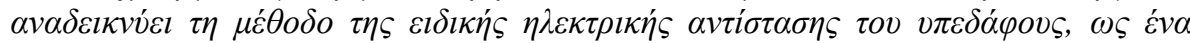

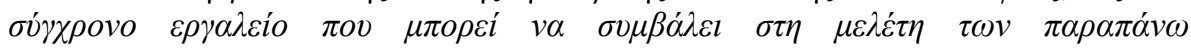

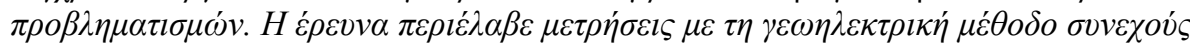

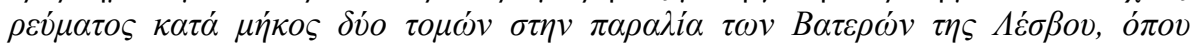

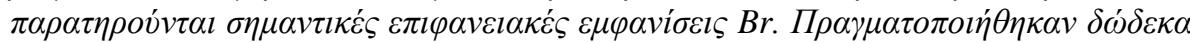

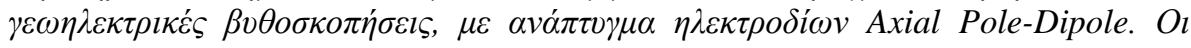

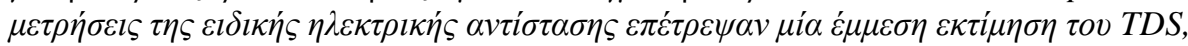

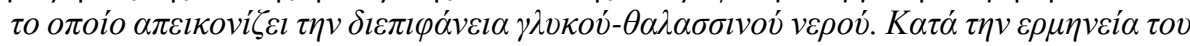




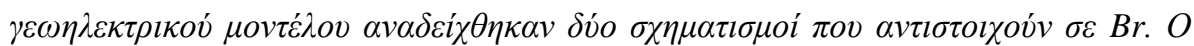

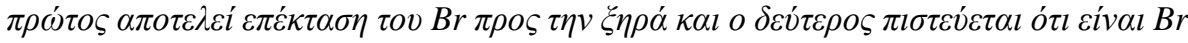

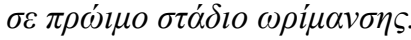

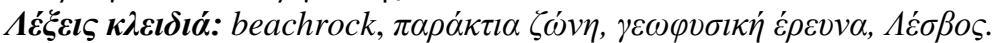

\section{Introduction}

Beachrock ( $\mathrm{Br}$ ) (or coastal sandstone) is encountered on the coastal zones as a modern and dynamicevolving phenomenon with a complex role of either degrading irreversibly the beach or in the case of submerged $\mathrm{Br}$ in protecting vulnerable beaches (Vousdoukas et al., 2007). Overviews of the $\mathrm{Br}$ appearance worldwide, characteristics, origin and morphodynamic evolution and impacts and possible usage are mainly described in two review papers of Vousdoukas et al. (2007) and Danjo and Kawasaki (2012). Br is found mostly in the tropics - subtropics and temperate shores, its form and orientation varies greatly and they are mainly identified beneath a coastal sediment cover within the transitional mixing zone as a resulting effect of sea and coastal water interaction under the supratidal zone conditions (e.g.Erginal et al., 2010; Caron, 2012).

The Gulf of Vatera is located on the south coast of Lesvos island in the northeastern Aegean Sea (Figure 1). It is a long curved beach, it has a total length of about $7 \mathrm{~km}$, being less than $50 \mathrm{~m}$ in width and it is confined in-between two small rivers -the Armyropotamos to the west and Vourkopotamos to the east-, whereas smaller ephemeral streams drain mainly to the eastern part of the beach. The wider coastal area is bounded by two rocky capes, Agios Fokas to the west and a high and tectonically affected coastal cliff to the east. Along specific parts of the beach there is significant appearance of $\mathrm{Br}$, which has been the subject of previous studies (Vousdoukas et al., 2007, 2009). However, it remains under investigation (i) the importance of the interaction of the dynamically changing coastal environment with the temporal changing surficial and underground hydrogeological balance (freshwater-saltwater mixing and its interaction/effect with the $\mathrm{Br}$ during its leakage) and (ii) whether the spatial distribution and the evolution of $\mathrm{Br}$ is in direct relation to the specific "host" coastal zone geo-environment. Within this framework a small scale geoelectrical survey was carried out, as part of an ongoing geophysical study, by using the Direct Current (DC) resistivity method in order to outline the subsurface spatial distribution of $\mathrm{Br}$ and adjacent coastal formations as well as their geoelectric characteristics, which could lead to useful conclusions regarding the geological host environment and to delineate the saline - fresh water transitional zone, so as to study its possible influence in the Br formation. Geophysical surveys focused on mapping $\mathrm{Br}$ are rather scarce (if absent) in the literature, with those of Psomiadis et al. (2009) and Kubo et al. (2013) being the most recent ones.

\section{General Beachrock characteristics}

The $\mathrm{Br}$ is either fragile or well laminated sedimentary rock or 'hard' coastal sedimentary formations or stratified sandstones, originating from the mixing of the various geological coastal materials (e.g. sand, pebbles etc.) (eg. Rey et al., 2004). Br is formed within the coastal zone quickly (probably within a year). It can record any morphological change along the coastline (Coxet et al., 2008). Moreover it can alter the physical nature of beaches and impact on the ecology (Brattström, 1992), the balance, the supply and the distribution of sediments along the coast, presenting seasonal morphological changes that differ from the expected ones (e.g. Rey et al., 2004; Vousdoukas et al., 2007; Psomiadis et al., 2009). The changes in the transitional zone (mixing freshwater - seawater) in coastal areas play an important role in the genesis of Br. It exhibits a wide variation of physical characteristics related to a cementation process and therefore to the properties of the consolidated mass (Rutten, 2011). The connective - adhesive material of $\mathrm{Br}$ is carbonate, stemming from direct precipitation from seawater or fresh water (Kelletat, 2006). Porosity, permeability, energy conditions (waves, currents), the geographic location and the local weather conditions and water temperature determine the course of cementation (e.g. Chowdhury et al., 1997). Dolomitization 
and $\mathrm{CO}_{2}$ degassing lead to mineralogical changes and create $\mathrm{Br}$ (e.g. Back et al., 1983; Arrieta et al., 2011). Also an important role must play the biological activity (role of bacteria in the cementing process) (e.g. Neumeier, 1999). Besides, the rainwater acts as the "carrier" of chemical and biological elements through surface and subsurface environments.Moreover, their formation might be affected by the morphology and the structure of the coastal zone and their interaction with the coastal hydrodynamics (Scoffin kal Stoddart, 1983; Shinn, 2009; Vousdoukas et al., 2009; Arrieta et al., 2011).

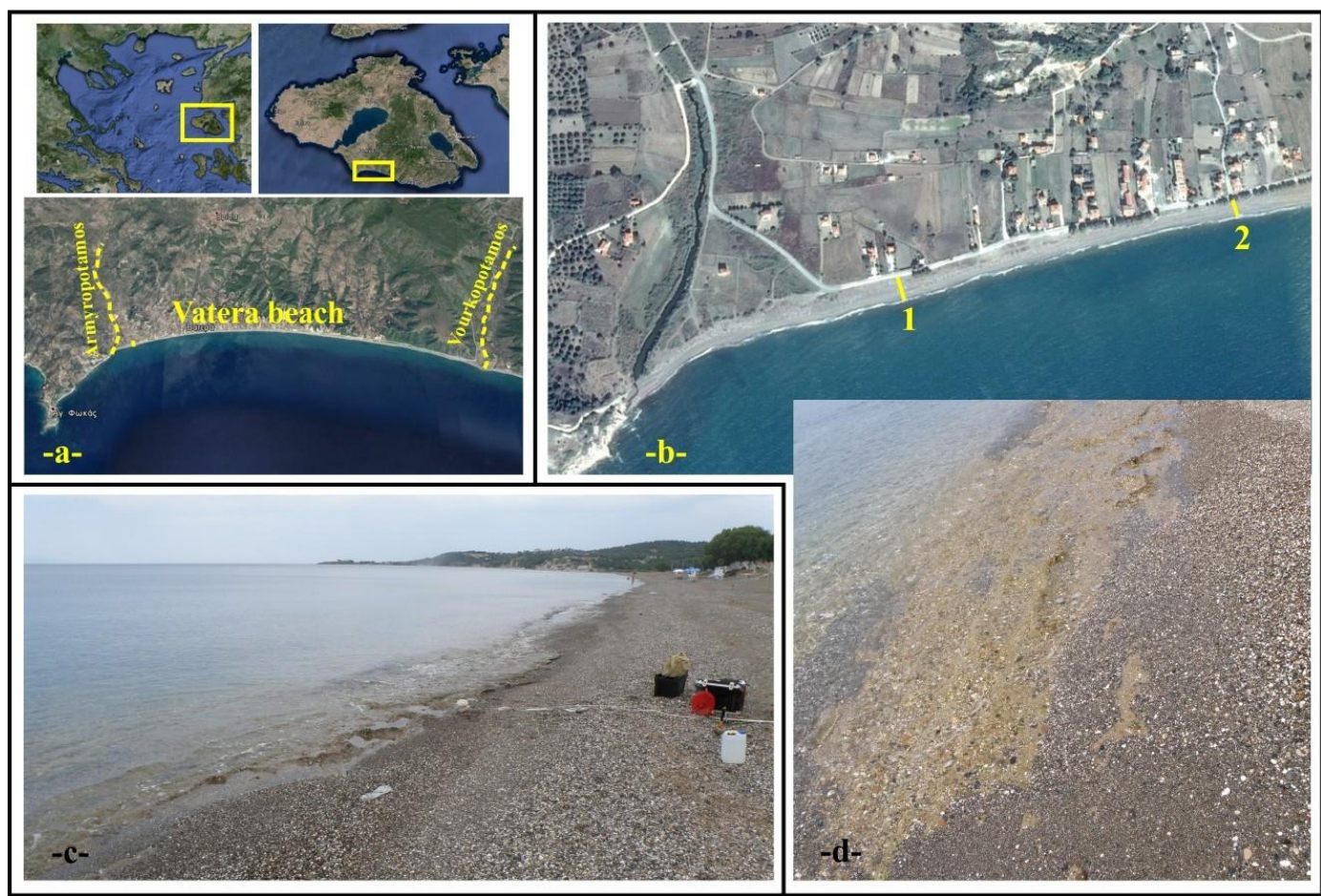

Figure 1 - (a) Location of the study area in Lesvos island, (b) position of the profiles presented in figure 4, (c) photo of profile 2 next to the Br outcrop and (d) a closer image of the Br outcrop along the shoreline.

\section{Methodology}

It is widely known that there is a relationship between the electrical conductivity and the physical characteristics and rock properties (e.g. the conductivity of the water filled pores, the porosity and the degree of saturation of the formation etc.). The DC resistivity method can determine the electrical properties of rocks and specifically the apparent electrical resistivity $\rho$ (ohm.m) by measuring the intensity I of the electric current supplied to the subsoil by a pair of electrodes (current electrodes) and the voltage $\Delta \mathbf{V}$ recorded in a separate pair of electrodes (potential electrodes) principally located in an intermediate position between the current electrodes (Figure 2 and Equation 1).

\section{Equation 1 - apparent electrical resistivity $\rho$}

$\rho=\mathrm{K}(\Delta \mathrm{V} / \mathrm{I})$

where $\mathbf{K}$ is a coefficient depending on the geometry of the electrode array being used (Telford et al., 1981). The determination of electrical resistivity at different depths within the Earth is achieved by taking a series of measurements of the above physical quantities for successively increasing current and potential electrode spacing. This process is called Vertical Electrical Sounding (VES). One of the most common electrode configurations is that introduced by Schlumberger (Equation 2). 
Equation 2 - geometric coefficient $K$

$\mathrm{K}=\pi(\mathrm{AB} / 2)^{2} / \mathrm{MN}$

where $\mathrm{AB}$ and $\mathrm{MN}$ are the distances between the two current and the two potential electrodes, respectively (Figure $2 \mathrm{a}$ ).

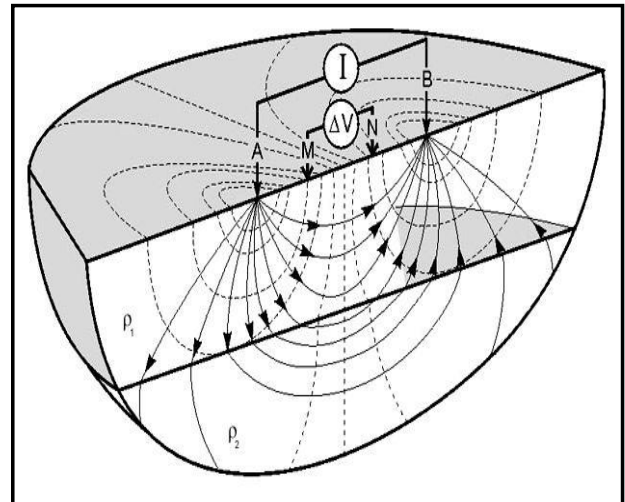

(a)

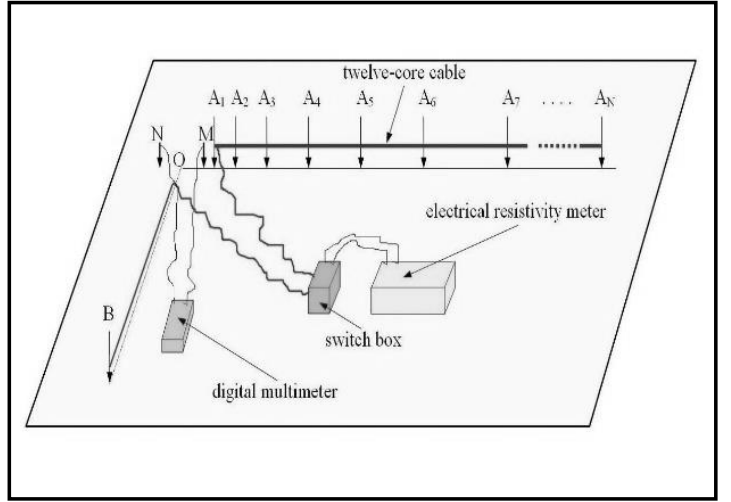

(b)

Figure 2 - (a) The basic configuration of current (A, B) and potential $(\mathrm{M}, \mathrm{N})$ electrodes in the VES method (continuous curved lines: electric current lines; dashed curved lines: equipotential lines of electric field between current electrodes (from geoFact, 2014). (b) Equipment setup for the Axial Pole-Dipole array.

The electrical resistivity $\boldsymbol{\rho}$ of rocks can be determined as a function of depth by increasing successively the distance between the two current electrodes. For a total number of $\mathrm{N}$ distances between the current electrodes, the apparent electrical resistivity $\boldsymbol{\rho}_{\mathbf{n}}$ corresponding to each distance using equation (1) is:

\section{Equation 3 - apparent electrical resistivity $\rho_{n}$ relative to the $n$-th measuring distance $A_{n} B / 2$}

$\rho_{\mathrm{n}}=\mathrm{K}_{\mathrm{n}}\left(\Delta \mathrm{V}_{\mathrm{n}} / \mathrm{I}_{\mathrm{n}}\right)$

where $\mathbf{n}=1,2,3, \ldots \mathrm{N}$ and $\Delta \mathbf{V}_{\mathbf{n}}$ the potential difference, $\mathbf{I}_{\mathbf{n}}$ the electric current intensity and $\mathbf{K}_{\mathbf{n}}$ the geometric coefficient relative to each current electrode distance $A_{n} B / 2$.

In this study, $\mathbf{I}$ and $\boldsymbol{\Delta} \mathbf{V}$ measurements were performed using a version of the widely known Schlumberger electrode array (Telford et al., 1981) that is known either as «half-Schlumberger» (Akintorinwa and Abiola, 2012), or as «Axial Pole-Dipole» array (Chandra et al., 2004). The main criteria for the selection of this particular electrode configuration was first ensuring less time and employees to conduct measurements and second the applicability of the method in a relatively limited space. According to this method, one of the two current electrodes (e.g. the current electrode $B$ ) is placed at a fixed point, at a large distance (about 3 times the maximum $A B / 2$ ) away from the centre $\mathrm{O}$ of the array and in a way that $\mathrm{OB}$ is perpendicular to $\mathrm{OA}$ (Figure $2 \mathrm{~b}$ ). Then electrode $\mathrm{A}$ is moved successively at the prescribed positions $A_{1}, A_{2}, A_{3}, \ldots, A_{N}$, where $N$ is the total number of measurements. The apparent electrical resistivity $\boldsymbol{\rho}_{\mathbf{n}}$, which corresponds to each of the distances $A_{n} B / 2$ is calculated by combining equations (2) and (3), however, the potential difference $\Delta \mathbf{V i s}$ now doubled in order to balance for the loss of half of the voltage gradient measured at the potential electrodes $\mathrm{M}$ and $\mathrm{N}$.

In order to demonstrate the sea water - fresh water mixing, the total dissolved salts (TDS) distribution was estimated (Bernard, 2006) by using equation 4 and under the assumption that the loose coastal geological formations (fluvial-alluvial, coastal sediments etc.) permit sea water presence in the coastal area. 


\section{Equation 4 - Total Dissolved Salts}

$\operatorname{TDS}(\mathrm{mg} / \mathrm{l})=0.7 \sigma$

where $\sigma=$ electrical conductivity $(\mu \mathrm{S} / \mathrm{cm})=10000 /$ electrical resistivity (ohm.m).

\subsection{Data Collection and Processing}

The electrical resistivity measurements were carried out using a measuring system, consisting of a DC resistivity meter designed and developed by Galanopoulos and Kolettis (2005) and a twelve core cable connected to the meter via a mechanical switch box (Figure 2b). The field measurements were carried out during May 2014 and comprised 12 «Axial Pole-Dipole» VES, located along 2 profiles of SSW-NNE direction (Figure 1). All VES had a maximum AB/2 of $13 \mathrm{~m}$. Profile 1 is $25 \mathrm{~m}$ long and consists of 7 VES having a spacing of $2-5 \mathrm{~m}$. Profile 2 is shorter (16m long) and consists of 5 VES having a spacing of $4 \mathrm{~m}$. Outcropping Br was detected only in profile 2 along the coastline and the measurements started directly next to the outcrop (Figure 1).

For each current electrode distance $A_{n} B / 2$, the data collection consisted of measurements of electric current intensity $\mathbf{I}$, the voltage $\Delta \mathbf{V}$ and the self-potential (SP) of the Earth. $\mathbf{S P}$ is the potential difference measured between the potential electrodes $\mathrm{M}$ and $\mathrm{N}$ in the absence of any artificial current flow. This potential difference is due either to bioelectric activity in vegetation, varying electrolytic concentrations in ground water or to the flow of natural electric currents (telluric currents) within the Earth, which are induced by the varying magnetic field of the Earth as a result of various magnetospheric and ionospheric phenomena (Telford et al., 1981). SP was taken into account in each measurement of $\mathbf{I}$ and $\Delta \mathbf{V}$, by subtracting its value from the corresponding value of $\boldsymbol{\Delta} \mathbf{V}$.

Application of equations (1)-(3) to the 12 VES data sets lead to the construction of an equal number of VES curves of apparent electrical resistivity versus AB/2 (Figure 3). The data processing of each VES was completed with the preparation of a one (1-D) dimensional geoelectric model (Figure 3) using JOINTEM, a geophysical modelling and interpretation software of EM and VES data made by Pirttijärvi (2014).

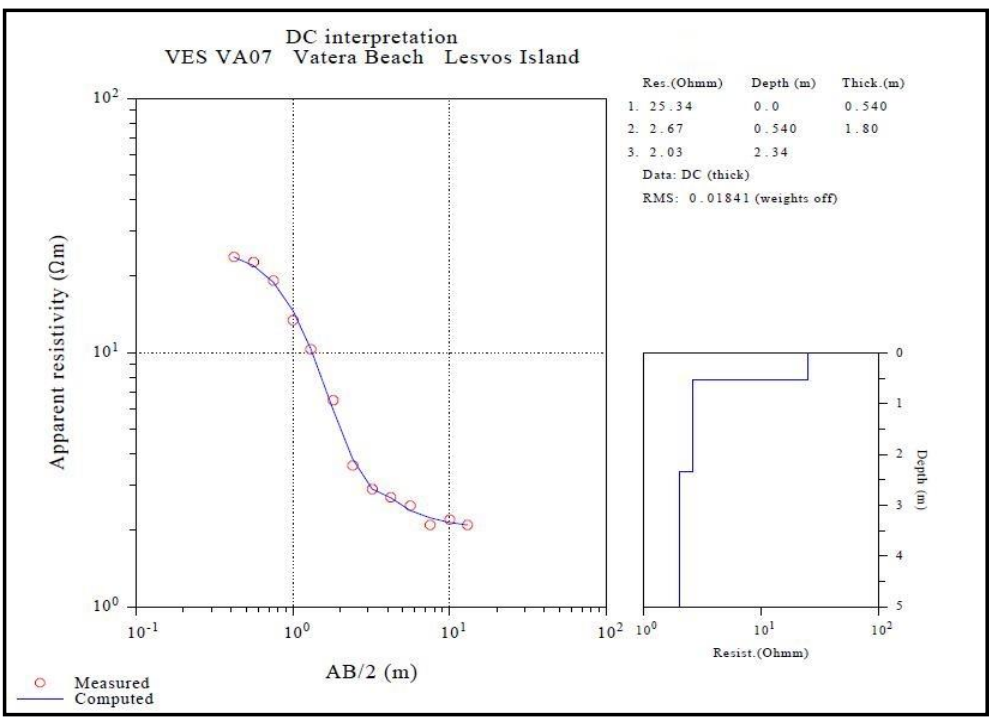

Figure 3 - Apparent electrical resistivity versus AB/2 and 1-D electrical model for VES7.

\section{Results and Discussion}

Appropriate combination of the derived 1-D models resulted in two geoelectric cross-sections showing the variation of the subsurface electrical resistivity with depth (Figure 4). Both geoelectric 
cross-sections designate a similar subsurface electrical structure. The deepest common feature is a very low resitivity (0.5-2.0 ohm.m) geoelectric basement, whose thickness is $1-3 \mathrm{~m}$ at Profile 1 and $1-5 \mathrm{~m}$ at Profile 2 . The depth to the top of the basement varies from sea level to $\sim 4.5 \mathrm{~m}$ below sea level. This figures the expected seawater intrusion, which has either filled the pores of the existing geological structures or has been mixed up with fresh water. In order to support the above interpretation with respect to the sea water - fresh water mixing the total dissolved salts (TDS) distribution below profile 1 is provided in figure 5 .
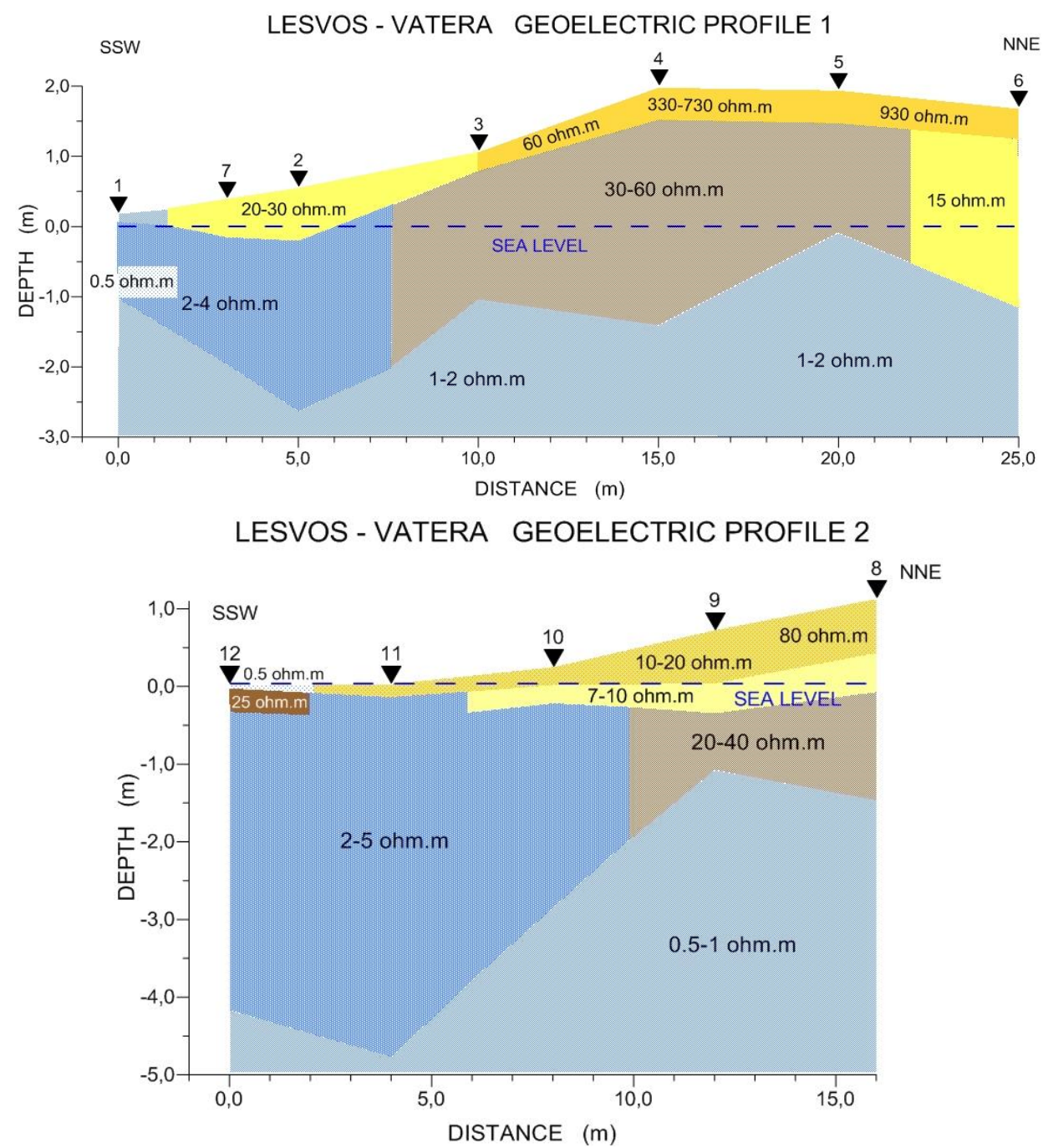

Figure 4 - Geoelectric cross sections compiled from 1-D models along Profile 1 (a) and Profile 2

(b).

The geoelectric basement is overlain by a less uniform and relatively more resistive (2.0-60.0 ohm.m) intermediate layer in both profiles, probably indicating a gradual decrease of the sea water content in the coastal aquifer. The main characteristic of this layer is the gradual, lateral increase in resistivity from 2.0 to $60.0 \mathrm{ohm} . \mathrm{m}$ at Profile 1 and 2.0-40.0 ohm.m at Profile 2, towards a NNE direction. The only difference is that at the NNE end of profile 1, the resistivity of this layer drops to $15.0 \mathrm{ohm} . \mathrm{m}$, suggesting a different geoelectical formation that can be attributed to an alluvialfluvial deposit, where fresh water content is most probably higher, also due to its geographical position, near the adjacent Armyropotamos river. 
On top of this intermediate layer there is a surficial more resistive unit (10.0-900.0 ohm.m), which is also characterized by a gradual, lateral increase in electrical resistivity, towards the NNE. This feature is interpreted in terms of the expected gradual lateral decrease of the sand moisture that is more prominent along Profile 1, because of the more intense topography and the distance from the coastline.

Along profile 2, which is situated immediately next to a surface $\mathrm{Br}$ outcrop along the shoreline (at VES12), the following geoelectical characteristics are figured: (i) there is a $25.0 \mathrm{ohm} . \mathrm{m}$ thin $(0.35 \mathrm{~m})$ structure that is the subsurface extension of the adjacent $\mathrm{Br}$ outcrop, (ii) a 7-10.0 ohm.m geoelectric structure is observed to the NNE, which is believed to be the lateral extension of $\mathrm{Br}$, sandwiched in between the surficial highly resistive unit and the intermediate layer, and (iii) the 7-10.0 ohm.m geoelectric structure has the same geometrical characteristics (thickness) and it is detected almost at the same elevation relative to the mean sea-level, with the observed $\mathrm{Br}$.

The $25.0 \mathrm{ohm}$.m block underlies a $0.5 \mathrm{ohm}$.m surficial layer that correlates with the presence of a sea-water saturated, unconsolidated sand.

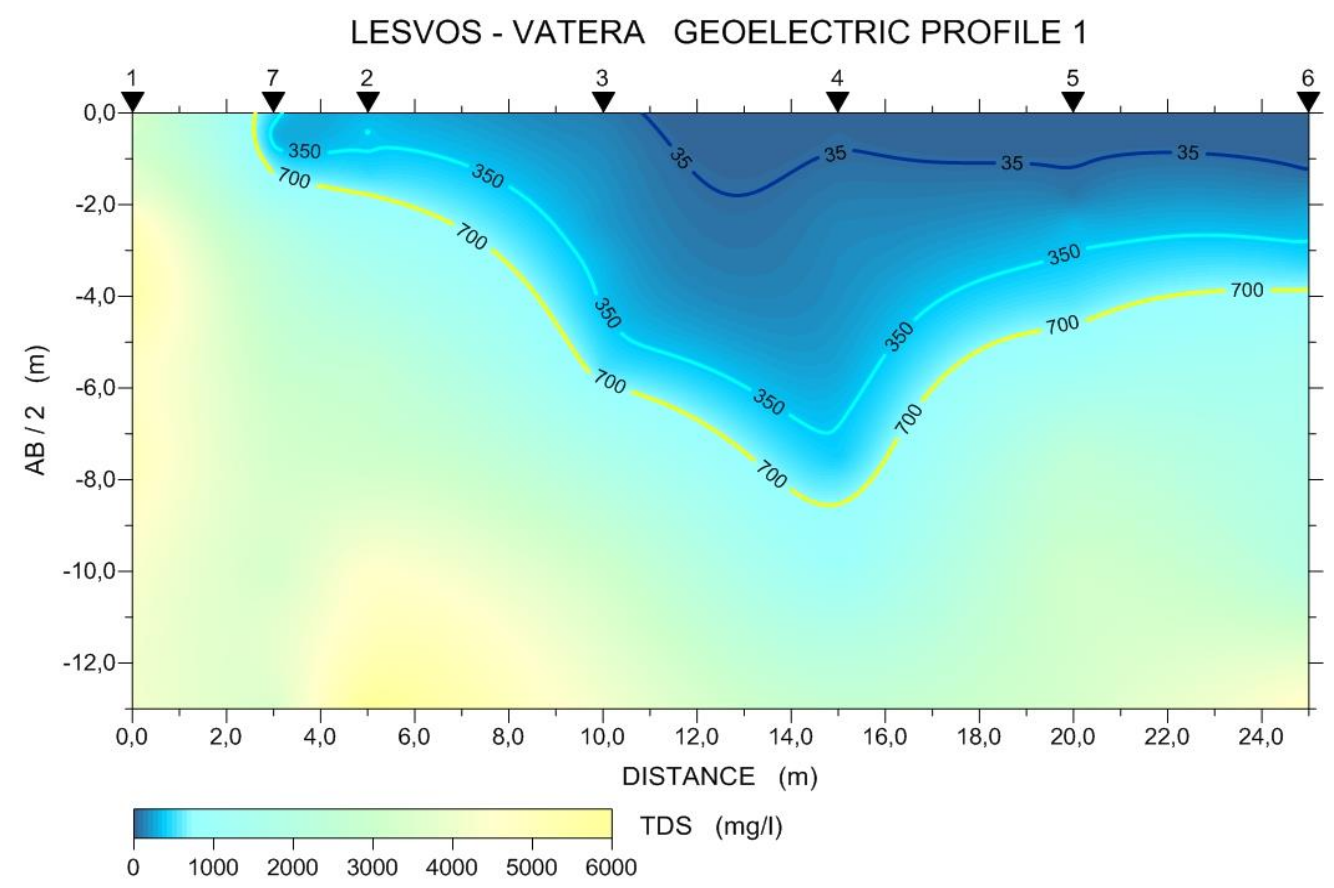

Figure 5 - Distribution of TDS as a function of AB/2, bellow profile 1.

Psomiadis et al. (2009) used electrical resistivity tomography for mapping the subsurface extend of $\mathrm{Br}$ between the villages Sotira and Kallirahi, in the western part of Thasos Island in Greece. The method gave reliable results in relation to in situ observations of the depth and dimensions of $\mathrm{Br}$, which was identified with rather very low electrical resistivities of about 2-15 ohm.m. Kubo et al. (2013) employed both the DC resistivity and seismic methods to investigate Br on Yagaji Island in Japan, where it was found to have low electrical resistivities of about 4-40 ohm.m, small thickness of about $1 \mathrm{~m}$ with a tendency to become thicker closer to the sea. During this survey in Vatera beach two thin formations with different geoelectrical characteristics, but being almost similar in thickness and in topographic level are attributed to $\mathrm{Br}$ of successive maturity stages. The submerged formation near the coastline, although limited in extent, has a uniform electrical resistivity value of $25 \mathrm{ohm} . \mathrm{m}$, whereas the buried formation towards the inner part of the beach has low electrical resistivity values (7-10 ohm.m), however within the range observed elsewhere (Psomiadis et al., 2009; Kubo et al., 2013) and probably resembles to a primary stage of Br build up. This hypothesis is supported by 
Vousdoukas et al. (2007, figure 4 of that paper), who ground-truthed a buried beachrock, about $1000 \mathrm{~m}$ besides profile 2 , after mechanical removal of the overlying unconsolidated beach sediments. The surficial sediments had a wedge-shape, similar to those of profile 2, whereas the detected $\mathrm{Br}$ had a similar texture to that of the ambient sedimentary material.

Employment also of other geophysical methods (dipole-dipole geoelectric method, magnetic, seismics) together with geotechnical and geochemical testing of the different $\mathrm{Br}$ formations and monitoring in different seasons would support and verify the findings of successive stages of $\mathrm{Br}$ build up and extend.

\section{References}

Akintorinwa, O.J. and Abiola, O., 2012. Comparison of Schlumberger and modified Schlumberger arrays VES interpretation results, Research Journal in Engineering and Applied Sciences, 1(3), 190-196.

Arrieta, N., Iturregi, I., Martinez-Arkarazo, X., Murelaga, J.I., Baceta and Madariaga, J.M., 2011. Spectroscopic characterization of ferruginous cements in a temperate beachrock formation close to Nerbioi-Ibaizabal estuary (Tunelboka cove, Bay of Biscay), CORALS II Conference.

Back, W., Hanshaw, B.B., Plummer, L.N., Rahn, P.H., Rightmire, C.T. and Rubin, M., 1983. Process and rate of dedolomitization Mass transfer and $14 \mathrm{C}$ dating in a regional carbonate aquifer, Geological Society of America Bulletin, 94, 1415-1429.

Bernard, J., 2006. Training course on electrical methods, IRIS instruments, 1-29 pp.

Brattstrom, H., 1992. Marine biological investigations in the Bahamas. Littoral zonation at three Bahamian beachrock localities, Sarsia, 77, 81-109.

Caron, V., 2012. Geomorphic and Sedimentologic Evidence of Extreme Wave Events Recorded by Beachrocks: A Case Study from the Island of St. Bartholomew (Lesser Antilles), Journal of Coastal Research, 811-828.

Chandra, S., Anand Rao, V. and Singh, V.S., 2004. A combined approach of Schlumberger and axial pole-dipole configurations for groundwater exploration in hard-rock areas, Current Science, 86(10), 1437-1443.

Chowdhury, S.Q., Fazlul Haq, A.T.M. and Hasan, K., 1997. Beachrock in St. Martin's Island, Bangladesh: Implication of sea level changes on beachrock cementation, Marine Geology, 120, 89-104.

Cox, R.T., Lumsden, N.D., Gough, K., Lloyd, R. and Talnagi, J., 2008. Investigation of late Quaternary fault block uplift along the Motagua/Swan Islands fault system: Implications for seismic/tsunami hazard for the Bay of Honduras, Tectonophysics, 457, 30-41.

Danjo, T. and Kawasaki, S., 2014. Characteristics of Beachrocks: A Review, Geotech. Geol. Eng., 32, 215-246.

Erginal, A.E., Kiyak, N.G. and Ozturk, B., 2010. Investigation of beachrock using microanalyses and OSL dating: a case study from Bozcaada Island, Turkey, Journal of Coastal Research, 26(2), 350-358.

Galanopoulos, D. and Kolettis, G., 2005. Investigating the formation of a superficial fracture on Nisyros Island, Greece with the DC resistivity method. In: Fytikas, M. and Vougiougalakis, G., eds., THE SOUTH AEGEAN ACTIVE VOLCANIC ARC, 7, Present Knowledge and Future Perspectives, Developments in Volcanology, 7, 227-240.

GeoFact, 2014. Geoelectrics, geoFact GmbH, Available online at: http://www.geofact.de/?page_id=110\&language=en.

Kelletat, D., 2006. Beachrock as Sea-Level Indicator? Remarks from a Geomorphological Point of View, Journal of Coastal Research, 22(6), 1558-1564.

Kubo, R., Kawasaki, S., Suzuki, K., Yamaguchi, S. and Hatta, T., 2013. Beachrock mapping by geophysical exploration: Application to Yagaji Island in Okinawa, Japan. Rock Mechanics for Resources, Energy and Environment, Kwasniewski and Lydzba, eds., Taylor \& Francis Group, London, ISBN 978-1-138-00080-3. 
Neumeier, U., 1999. Experimental modelling of beachrock cementation under microbial influence, Sedimentary Geology, 126(1-4), 35-46.

Pirttijärvi, M., 2014. Free Software from Markku Pirttijärvi, Joint Inversion of EM and VES data, Available online at: https://wiki.oulu.fi/pages/viewpage.action?pageId=20677943.

Psomiadis, D., Tsourlos, P. and Albanakis, K., 2009. Electrical resistivity tomography mapping of CS: application to the island of Thassos (N. Greece), Environmental Earth Sciences, 59(1), 233-240.

Rey, D., Rubio, B., Bernabeu, A.M. and Vilas, F., 2004. Formation, exposure, and evolution of a high-latitude beachrock in the intertidal zone of the Corrubedo complex (Ria de Arousa, Galicia, NW Spain), Sedimentary Geology, 169(1-2), 93-105.

Rutten, L.G., 2011. Interactions between beachrock formations and shoreline evolution. Case study: Togo, Section for Geo-Engineering, Department of Applied Earth Sciences, Delft University of Technology, The Netherlands.

Scoffin, T.P. and Stoddart, D.R., 1983. Beachrock and intertidal sediments. In: Goudie, A.S. and Pye, K., eds., Chemical Sediments and Geomorphology, Academic Press, London, 401-425.

Shinn, E.A., 2009. The Mystique of Beachrock, IAS Special Publication, 41, 19-28.

Telford, W.M., Geldart, L.P., Sheriff, R.E. and Keys, D.A., 1981. Applied Geophysics, Cambridge University Press.

Vousdoukas, M.I., Velegrakis, A.F. and Plomaritis, T.A., 2007. Beachrock occurrence, characteristics, formation mechanisms and impacts, Earth-Science Reviews, 85, 23-46.

Vousdoukas, M., Velegrakis, A. and Karambas, T., 2009. Morphology and sedimentology of a microtidal beach with beachrocks: Vatera, Lesbos, NE Mediterranean, Continental Shelf Research, 29(16), 1937-1947. 